\title{
Antagonic activities of Trypanosoma cruzi metacaspases affect the balance between cell proliferation, death and differentiation
}

\author{
M Laverrière ${ }^{1}$, JJ Cazzulo ${ }^{1}$ and VE Alvarez ${ }^{\star, 1}$
}

\begin{abstract}
Metacaspases are distant relatives of animal caspases present in plants, fungi and protozoa. At variance with caspases, metacaspases exhibit stringent specificity for basic amino-acid residues and are absolutely dependent on millimolar concentrations of calcium. In the protozoan parasite Trypanosoma cruzi, metacaspases have been suggested to be involved in an apoptosis-like phenomenon upon exposure of the parasite to fresh human serum (FHS). Nuclear relocalization of metacaspases was observed after FHS treatment and overexpression of metacaspase- 5 led to enhanced sensitivity to this stimulus. Here we report some biochemical properties of $T$. cruzi metacaspases. Performing fluorescent-activated cell sorting (FACS) analysis of epimastigotes inducibly overexpressing metacaspase-3, we demonstrate a role for this metacaspase in cell cycle progression, protection of epimastigotes from naturally occurring cell death and differentiation to infective metacyclic trypomastigotes. We also show that regulation of metacaspase-3 activity is important for cell cycle completion inside the mammalian host. On the other hand, inducible overexpression of metacaspase-5 lacking its C-terminal domain caused an apoptotic-like response. These results suggest that the two $T$. cruzi metacaspases could play an important role in the life cycle and bring to light the close relationship between cell division, death and differentiation in this ancient unicellular eukaryote. Cell Death and Differentiation (2012) 19, 1358-1369; doi:10.1038/cdd.2012.12; published online 9 March 2012
\end{abstract}

Trypanosoma cruzi is the causative agent of Chagas disease: a chronic illness widespread in Central and South America still without any vaccine or efficient treatment. ${ }^{1}$ This protozoan parasite has a complex life cycle alternating between an insect vector and a mammalian host. ${ }^{1}$ Two predominant forms are present in the insect gut: the proliferating epimastigote and the infective G0-arrested metacyclic trypomastigote, pre-adapted for transmission, whereas the proliferative intracellular amastigote and the G0-arrested bloodstream trypomastigote are the predominant forms in the infected mammal. Different stimuli can induce an apoptosis-like response in the epimastigotes, among them are entry into the stationary phase, temperature shift from 28 to $37^{\circ} \mathrm{C}$ or exposure to fresh human serum (FHS). The latter kills epimastigotes but not the infective metacyclic trypomastigotes by complement activation. ${ }^{2}$ This apoptotic-like process was suggested to be advantageous to the infecting population, as an early immunological response of the host can be avoided by selecting pre-adapted trypomastigotes and by facilitating invasion of macrophages by phagocytosis of apoptotic bodies and trypomastigotes, as it has been described for Leishmania promastigotes. ${ }^{3}$ The molecular mechanisms mediating this apoptosis-like phenomenon have not yet been fully elucidated. ${ }^{4}$ The absence of caspases, the main molecular effectors of apoptosis, in the genome of
T. cruzi (as in all protozoa, fungi and plantae) has placed metacaspases as potential functional orthologues. Metacaspases (E.C. 3.4.22) are endopeptidases from the C14 family, clan CD, with a conserved catalytic His-Cys dyad and a predicted common caspase-haemoglobinase fold. ${ }^{5}$ Their substrate specificity is for basic residues at $\mathrm{P} 1$ position, making them unable to cleave caspase substrates. ${ }^{6}$ Evidences suggest that metacaspases modulate cell death, ${ }^{7-11}$ cell cycle progression ${ }^{12-14}$ and protein aggregation, ${ }^{15}$ but there is still controversy about their functions and their relation with caspases. ${ }^{16-18}$ The fact that metacaspases are not present in humans and fulfil important roles in trypanosomatids make them attractive drug targets, and a first series of inhibitors with trypanocidal activity has been developed recently. ${ }^{19}$ Trypanosomatid metacaspases can be distinguished by their overall domain composition and gene copy number. A single copy gene (termed LmjMCA in Leishmania major (L. major), TbMCA5 in Trypanosoma brucei and metacaspase-5 (TCMCA5) in T. cruzi) is present in all three trypanosomatids and encodes a protein that, in addition to the catalytic domain, bears a Pro-, GIn- and Tyr-rich C-terminal extension. In $T$. brucei and $T$. cruzi, but not in L. major, multiple copy genes lacking the $\mathrm{C}$-terminal region are also present (4 genes in $T$. brucei named TbMCA1-4 and about 16 genes in $T$. cruzi called metacaspase-3

${ }^{1}$ Instituto de Investigaciones Biotecnológicas IIB-INTECH, Universidad Nacional de San Martín - CONICET, Buenos Aires, Argentina

${ }^{*}$ Corresponding author: VE Alvarez, Instituto de Investigaciones Biotecnológicas IIB-INTECH, Universidad Nacional de San Martín - CONICET, Avenida General Paz 5445, San Martín, Buenos Aires 1650, Argentina. Tel: + 54114580 7255; Fax: + 54114752 9639; E-mail: valvarez@iib.unsam.edu.ar

Keywords: Trypanosoma cruzi; metacaspase; cell cycle; metacyclogenesis

Abbreviations: AMC, 7-amino-4-methylcoumarin; BHT, brain-heart infusion-tryptose medium; DAPI, 6-diamidino-2-phenylindole; DTT, dithiothreitol; eGFP, enhanced green fluorescent protein; FACS, fluorescent-activated cell sorting; FCS, foetal calf serum; FHS, fresh human serum; G418, Geneticin; HA, haemagglutinin; HEPES, $N$-[2-hydroxyethyl] piperazine- $N$-[2-ethanesulphonic acid]; HU, hydroxyurea; PBS, phosphate-buffered saline; PI, propidium iodide; PCR, polymerase chain reaction; TCMCA3, metacaspase-3; TCMCA5, metacaspase-5

Received 24.10.11; revised 18.1.12; accepted 19.1.12; Edited by G Salvesen; published online 09.3.12 
(TCMCA3)). Most sera from chronic chagasic patients contain antibodies specific for TCMCA3, but not TCMCA5, showing that TCMCA3 is expressed during natural infections. During FHS-induced cell death, both metacaspases translocate from the cytoplasm to the nucleus. Overexpression of full-length TcMCA5 enhances sensitivity to FHS-induced cell death; several attempts to obtain stable population of TCMCA3 overexpressors were unsuccessful. ${ }^{20}$ In this work, we describe some biochemical properties of $T$. cruzi metacaspases and the results of their overexpression, which suggest that $T$. cruzi metacaspases, like caspases in metazoans, may be involved in a broad spectrum of biological processes including the balance between cell choices. $^{21}$

\section{Results}

Metacaspases do not require proteolytic processing to display arginine-specific peptidase activity. Full-length forms of $T$. cruzi metacaspases tagged at the $\mathrm{N}$ terminus with six His residues, followed by a haemagglutinin (HA) epitope, and at the $\mathrm{C}$ terminus with a $3 \times$ Flag epitope were expressed in Escherichia coli (Figure 1a). Both purified TCMCA3 and TcMCA5 recombinant proteins hydrolyzed the fluorogenic peptide optimal for Arabidopsis thaliana metacaspase-9: Ac-Val-Arg-Pro-Arg-7-amino-4-methylcoumarin (Ac-VRPR$\mathrm{AMC}),{ }^{22}$ strictly depending on the presence of an intact His-Cys catalytic dyad (Figure 1b). Deletion of the N-terminal region almost abolished the enzymatic activity, suggesting that it is essential either for folding or activity of the enzymes, while deletion of the C-terminal extension in TcMCA5 produced a 2.6-fold increase in specific activity. The kinetic parameters for TCMCA3, TCMCA5 and TCMCA5 $\Delta \mathrm{Ct}$ using Ac-VRPR-AMC were determined. The $K_{\mathrm{m}}$ values obtained were very similar: $1.54 \pm 0.19,1.84 \pm 0.21$ and $2.09 \pm 0.24$ $\left(\times 10^{-4} \mathrm{M}\right)$, respectively, the $k_{\text {cat }}$ values obtained were $21 \pm 3,6 \pm 1$ and $17 \pm 2\left(\times 10^{-5} / \mathrm{s}\right)$, respectively, and $k_{\text {cat }} / K_{\mathrm{m}}$ values were $1.36 \pm 0.04,0.33 \pm 0.01$ and $0.81 \pm 0.02 / \mathrm{M} / \mathrm{s}$.

TCMCA3, TCMCA5 and TCMCA5 $\Delta \mathrm{Ct}$ are inhibited by EDTA (Figure 1c); however, TCMCA3 requires exogenous addition of calcium, but TCMCA5 does not, suggesting that the latter possesses higher metal-binding affinity and has already loaded the metal in the bacteria. Furthermore, while TcMCA5 activity is linear from 0 time, TCMCA3 activity increases gradually after calcium addition, being maximal and constant after $30 \mathrm{~min}$. This suggests that calcium could be mediating a conformational change in TCMCA3 leading to full activity.

We were not able to detect any self-proteolytic processing by western blot analysis of bacterial cell extracts, in samples of the purified recombinant proteins or even in the reaction mixtures after the activity assays. Figure 1d shows that the patterns of the full-length forms are almost identical to those of the active site mutants; the minor degradation bands observed can be attributed to the action of bacterial peptidases. The effect of calcium incubation on the recombinant proteins was evaluated by SDS-PAGE followed by Coomassie staining. We did not observe the appearance of lower molecular weight bands even after 90 min incubation (Figure 1e).
Inducible expression of metacaspases in epimastigotes of T. cruzi. As the absence of proteolytic processing found in vitro could be due to the need of additional activation factors or to the action of another peptidase not present in bacteria, we examined whether processing could occur in vivo. Overexpression of the enzymes was performed using the T. cruzi inducible vector pTcINDEX ${ }^{23}$ Epimastigote cell lines expressing similar versions of tagged metacaspases (Figure 2a) under the control of a tetracyclineregulated promoter were generated (Materials and Methods and Supplementary Figure 1A). Western blot analysis of whole-cell extracts revealed a significant accumulation of all constructs after the addition of tetracycline, at their expected molecular weights. This was confirmed not only under normal growth conditions (Figure $2 \mathrm{~b}$ ), but also when epimastigotes were exposed to different stress stimuli, including apoptosis induction with $\mathrm{FHS},{ }^{2}$ nutritional stress (phosphate-buffered saline, PBS), heat shock $\left(37^{\circ} \mathrm{C}\right)$ and endoplasmic reticulum calcium mobilization produced by cyclopiazonic acid (Supplementary Figure 2). In some cases, degradation products attributable to other proteinases were detected. We cannot discard, however, the possibility of processing under some specific condition, or processing of a minor fraction of the proteins, not detectable by western blot.

Expression of active metacaspases has a detrimental effect on epimastigote growth rate. We monitored the effect of metacaspase overexpression on epimastigote growth by counting cell numbers daily after protein induction. Figure $2 \mathrm{c}$ shows that all cell lines grew at similar rates in the absence of tetracycline, but those harbouring either full-length TCMCA3 or TCMCA5 lacking the C-terminal extension (TCMCA5 $\Delta \mathrm{Ct}$ ) showed differences when induced. Although TCMCA3 overexpressors exhibited a pronounced reduction in the growth rate already $48 \mathrm{~h}$ post-induction, TcMCA5 $\Delta$ Ct overexpressors were indistinguishable from the uninduced control until $96 \mathrm{~h}$ post-induction when epimastigotes reached the stationary phase of culture and the growth curve rapidly declined. Growth defects were not observed when less active (TCMCA5) or completely inactive $\left(T C M C A 3^{\mathrm{C} 223 \mathrm{~A}} T C M C A 5 \Delta \mathrm{Ct} \mathrm{C}^{\mathrm{C} 201 \mathrm{~A}}\right.$ and $T C M C A 5^{\mathrm{C} 201 \mathrm{~A}}$ ) variants were expressed, showing that the metacaspase proteolytic activity and not just protein overexpression is responsible for the observed phenotypes.

Active TcMCA3 arrests cell cycle in G1/S transition. To determine the cause of growth arrest, cultures of TcMCA3 transgenic epimastigotes were synchronized with respect to DNA synthesis using hydroxyurea $(\mathrm{HU})$ and progression through the cell cycle upon release of $\mathrm{HU}$ was evaluated by propidium iodide $(\mathrm{PI})$ staining and flow cytometry analysis. ${ }^{24}$ Figure 3a shows that for the uninduced cell line (TCMCA3-Tet), two peaks can be seen immediately after $\mathrm{HU}$ removal $(0 \mathrm{~h})$. The first peak represents the cells that become concentrated in the G1 and early S phases containing one nucleus $(2 n)$. The second peak represents the cells in G2/M (4n) that seem to be refractory to $\mathrm{HU}$ treatment and the remaining cells are in the $\mathrm{S}$ phase. At $6 \mathrm{~h}$ after $\mathrm{HU}$ removal, cells progress synchronically through the $S$ phase and reach the G2/M phase at $12 \mathrm{~h}$. Finally, $18 \mathrm{~h}$ upon release of $\mathrm{HU}$, cells had 
a

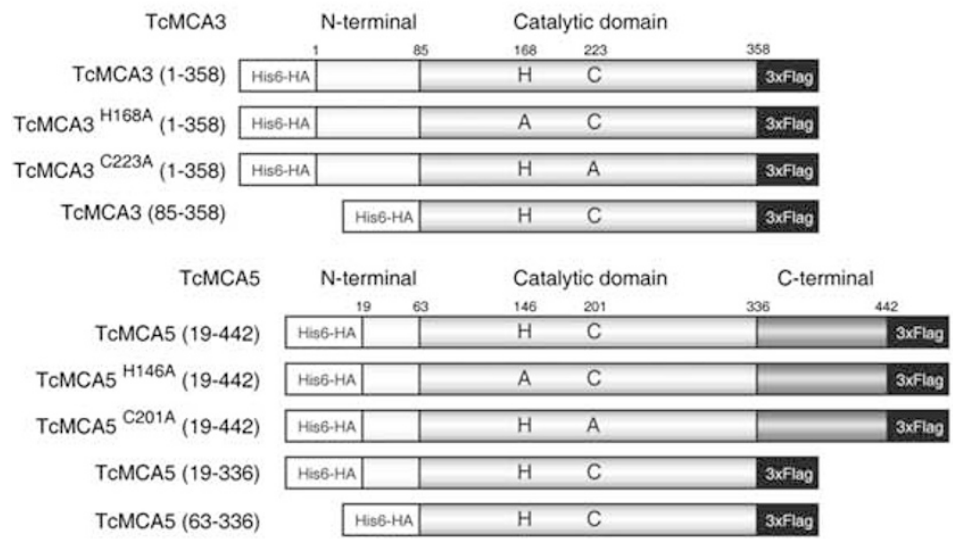

b

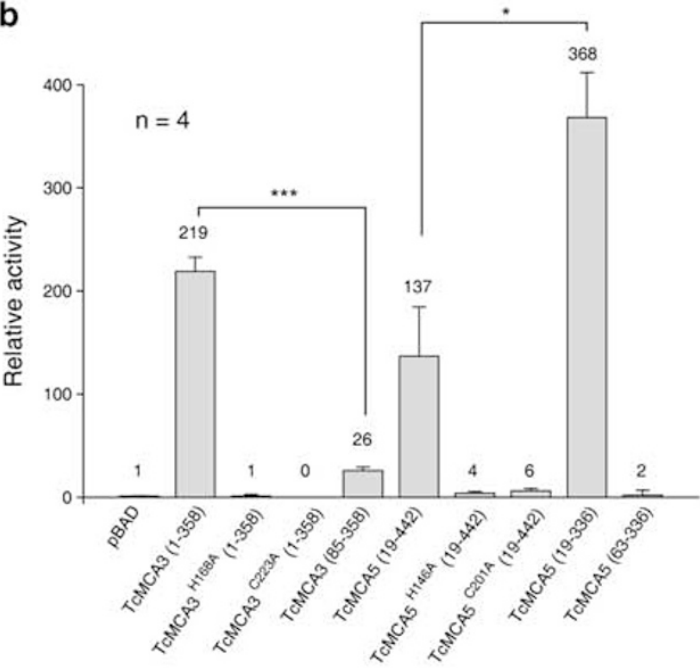

C
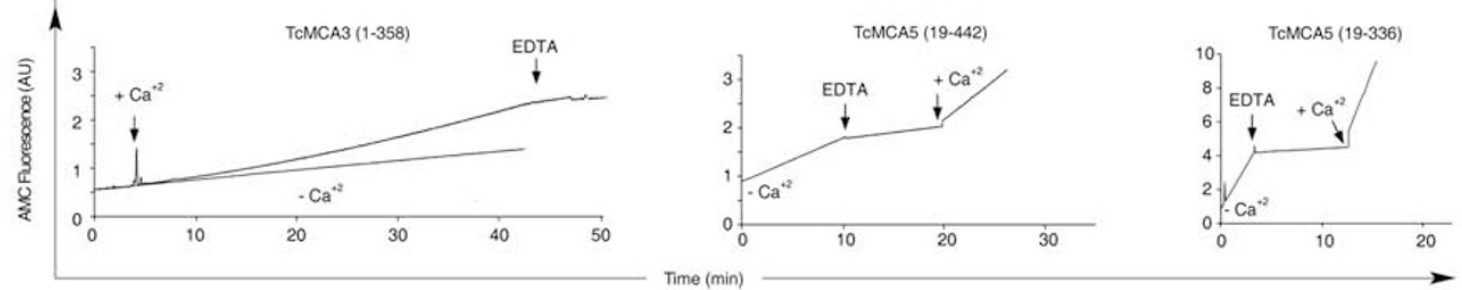

d

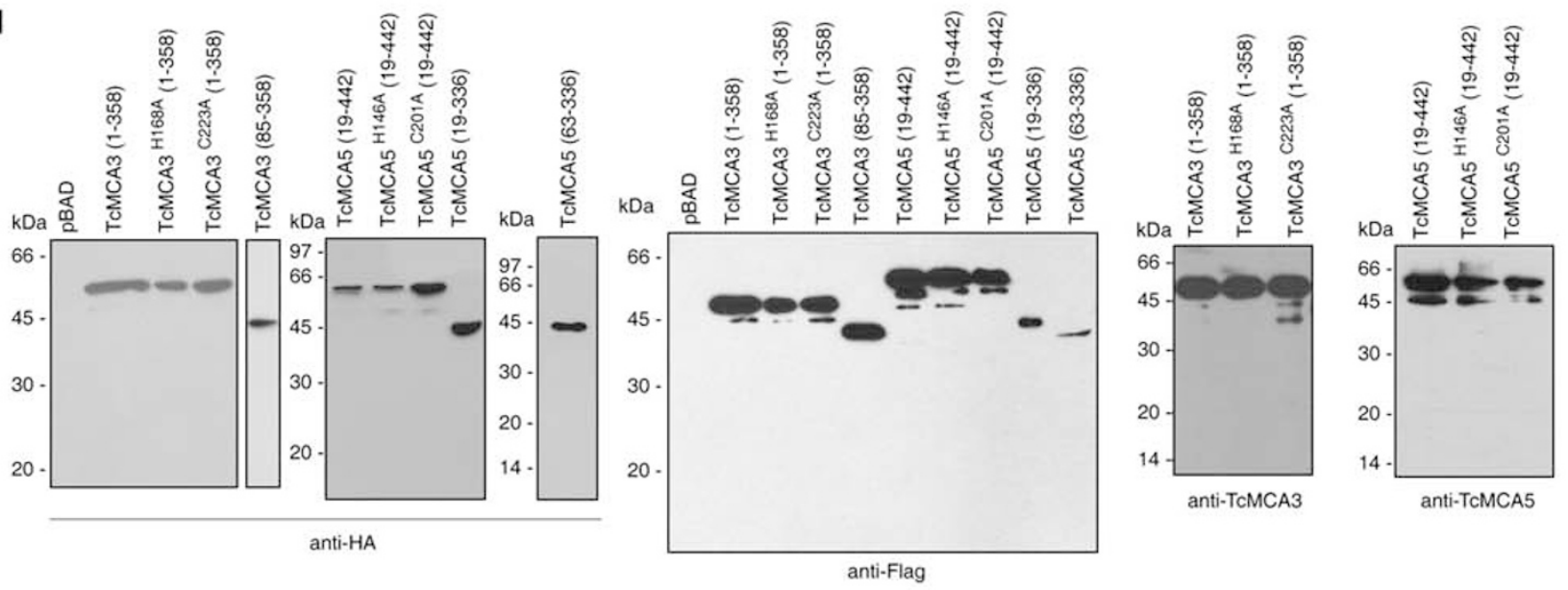

e

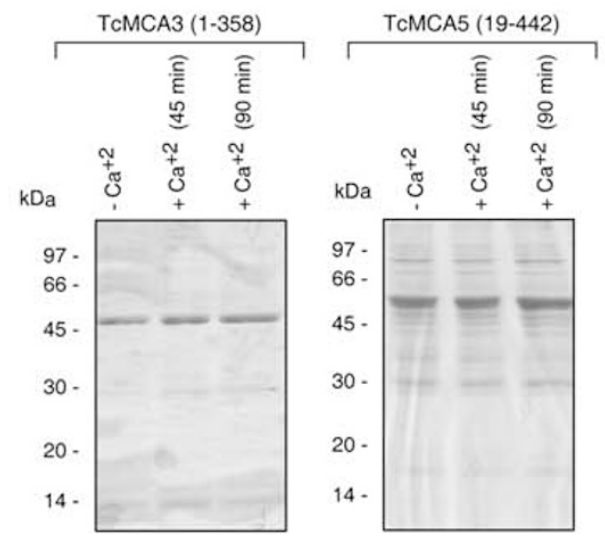


traversed through $\mathrm{G} 2 / \mathrm{M}$ and the $\mathrm{G} 1$ peak reappeared, indicating the start of the next cycle. In contrast, when the expression of TCMCA3 was induced by the addition of tetracycline (TCMCA3 + Tet), a clear delay in the entry into and completion of the DNA synthesis phase was observed (Figure $3 \mathrm{a}$, middle row). Note that $6 \mathrm{~h}$ after $\mathrm{HU}$ release, $57 \%$ of the cells are still in $\mathrm{G} 1$ and early $S$ phases (in contrast to $36 \%$ in control cells). Moreover, $12 \mathrm{~h}$ post-HU removal there is still a high proportion of cells at the same stage (33\% versus $16 \%$ in control cells), a higher number of cells in the S phase $(23 \%$ versus $14 \%$ in control cells) and a lower percentage of cells that were able to reach G2/M (44\% versus $70 \%$ in control cells), suggesting a transient G1/S cell division arrest. Protein induction $24 \mathrm{~h}$ preceding synchronization or after $\mathrm{HU}$ release produced similar results (data not shown). We also observed an increased number of metacyclic trypomastigotes at $72 \mathrm{~h}$ post-induction, at a time-point where metacyclics are normally absent. However, the low percentage of this form does not explain the observed cell cycle arrest. The parental cell line pLew13, and cell lines expressing TCMCA3 ${ }^{\mathrm{C} 223 \mathrm{~A}}$, TCMCA5, TCMCA5 ${ }^{\mathrm{C} 201 \mathrm{~A}}$, TCMCA5 $\Delta \mathrm{Ct}$ and $T c M C A 5^{\mathrm{C} 201 \mathrm{~A}} \Delta \mathrm{Ct}$ behaved as their corresponding uninduced controls (Figure $3 a$ lower row for induced TCMCA3 ${ }^{\mathrm{C} 223 \mathrm{~A}}$ and not shown for TCMCA5 variants). Protein expression at different time-points was confirmed by western blot analysis (Figure $3 b$ ). a

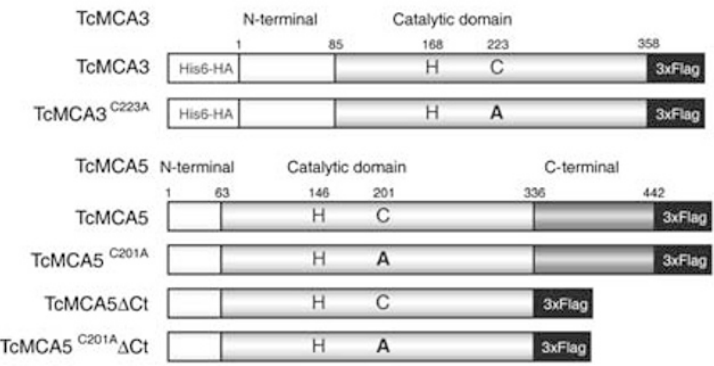

b

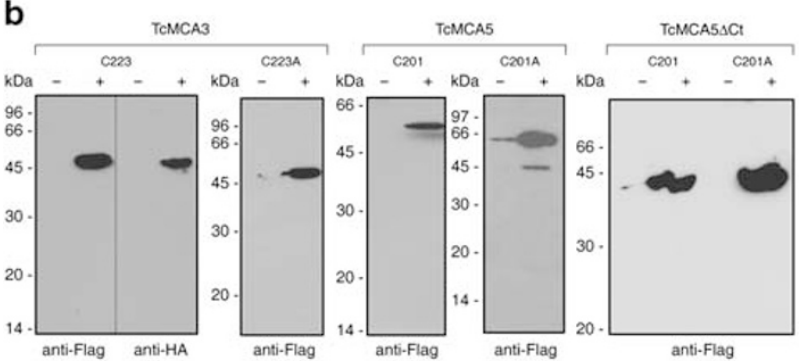

C

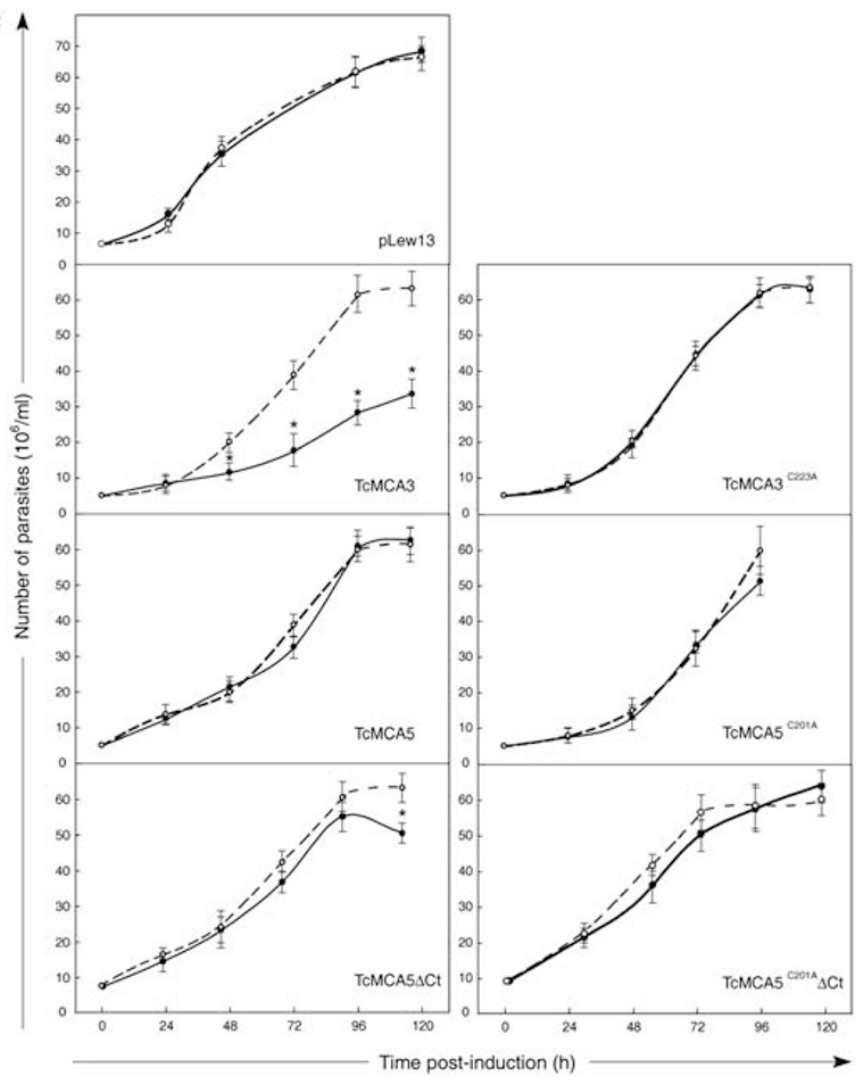

Figure 2 Inducible expression of metacaspases in epimastigotes. (a) Schematic representation of metacaspase constructs in the T. cruzi tetracycline-inducible vector pTCINDEX. (b) Cell lines harbouring transgenes encoding TCMCA3 active (C223) or inactive (C223A); TCMCA5 active (C201) or inactive (C201A) and TcMCA5 $A C t$ active (C201) or inactive (C201A) were grown in the absence $(-)$ or presence $(+)$ of tetracycline (Tet) for $60 \mathrm{~h}$ before cell lysates $\left(10^{7}\right.$ parasites per lane) were prepared and analyzed by western blot with anti-Flag or anti-HA antibodies. (c) Growth curve of wild-type (pLew13) epimastigotes and cell lines described in (b). Cells were grown in the presence (closed circles, continuous line) or absence (open circles, dashed line) of tetracycline and counted daily during 5 days. Results are representative of three independent experiments

Figure 1 Recombinant expression of T. cruzimetacaspases in bacteria. (a) Schematic representation of full-length, active site mutants and truncated versions of TcMCA3 and TCMCA5 in the bacterial expression vector pBAD24. Metacaspases were tagged at the $\mathrm{N}$ and $\mathrm{C}$ termini with $6 \times$ His-HA and $3 \times$ Flag, respectively. (b) Cleavage of substrate Ac-VRPR-AMC by full-length, active site mutants and truncated versions of purified recombinant TCMCA3 and TcMCA5 produced in E. coli measured by fluorometric assay as described in Materials and Methods. Activity is expressed as the fold increase relative to Ac-VRPR-AMC hydrolysis generated by mock (empty vector) purification. Means and S.D. from four independent experiments are indicated. Differences observed between values were statistically significant (Student's $t$-test). ${ }^{*} P<0.05$ and ${ }^{* * \star} P<0.001$. (c) Time course of substrate hydrolysis ( $150 \mu \mathrm{M}$ Ac-VRPR-AMC) by $20 \mu \mathrm{g}$ of purified recombinant protein (TCMCA3, TcMCA5 or TcMCA5 4 Ct). Additions of $10 \mathrm{mM}$ calcium or EDTA are indicated by arrows. (d) Western blot analysis of the reaction mixtures after the activity assays using anti-HA, anti-Flag, anti-TcMCA3 or anti-TCMCA5 antibodies. (e) Time-course experiment of recombinant proteins incubated with calcium and analyzed by SDS-PAGE, followed by Coomassie staining. Results are representative of at least three independent experiments 


\section{a}
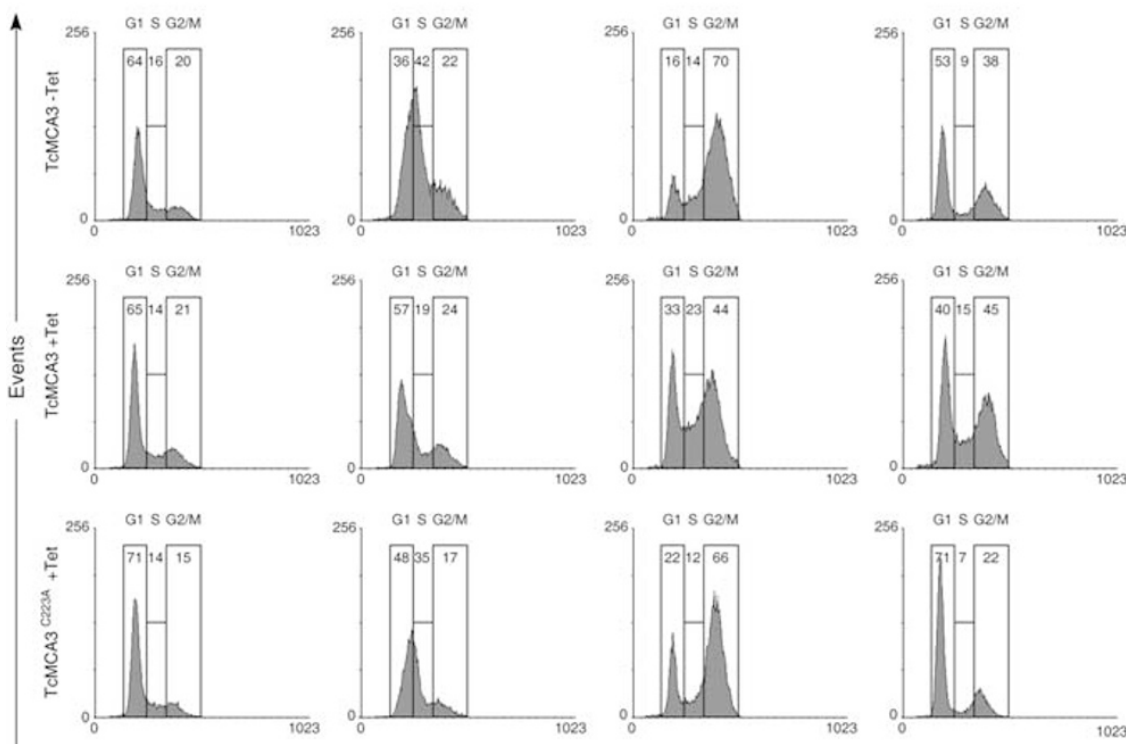

Oh

$48 \mathrm{~h}$

$6 \mathrm{~h}$

$12 \mathrm{~h}$

$18 \mathrm{~h}$

time post-HU release

$54 \mathrm{~h}$

$60 \mathrm{~h}$

$66 h$

time post induction

\section{b}
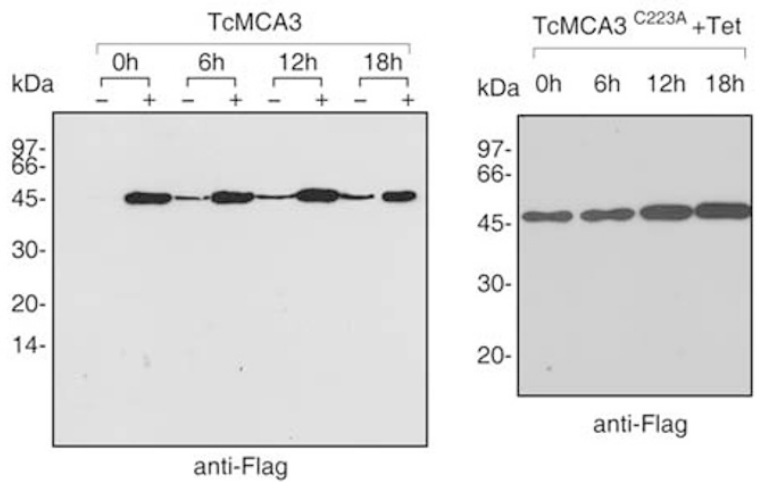

Figure 3 Overexpression of full-length TCMCA3, but not its active site mutant, arrests cell cycle in G1/S transition. (a) FACS analysis of the cell cycle progression of synchronized TCMCA3 transgenic epimastigotes in the absence (upper row) or in the presence (middle row) of tetracycline. A similar analysis was performed for the active site mutant-induced cell line (lower row). (b) Uninduced $(-)$ or induced $(+)$ cultures of TcMCA3 were analyzed by western blot $\left(10^{7}\right.$ parasites per lane) at different time points after $\mathrm{HU}$ removal $(0,6,12$ and $18 \mathrm{~h})$ using anti-Flag antibodies. For TCMCA ${ }^{\mathrm{C2} 23 \mathrm{~A}}$, only the induced cultures are shown

As TbMCA4 was demonstrated to be palmitoylated and located in the flagellum, ${ }^{25}$ we designed constructs with free $\mathrm{N}$ termini, TCMCA3-3 $\times$ Flag and TCMCA3-enhanced green fluorescent protein (TCMCA3-eGFP), which should not prevent palmitoylation. Parasites overexpressing both constructs presented the same phenotype as His-HA-TcMCA3-3 $\times$ Flag overexpressing parasites (Supplementary Figures $3 A-D$ for TCMCA3-3 $\times$ Flag and below for TCMCA3-eGFP).

The correct subcellular distribution of tagged TCMCA3 was confirmed by IFI analysis. TCMCA3-overexpressing parasites were evaluated using monoclonal antibodies to detect the tagged proteins and polyclonal antibodies (specific to TCMCA3) to detect both natural and tagged forms. Tagged metacaspases displayed a similar subcellular localization to that of their natural counterparts, ${ }^{20}$ and colocalization experiments showed a complete overlapping of both signals (Supplementary Figure 3E).
It has been reported when using pTcINDEX vector that protein induction does not occur at the same rate or to the same degree in all cells even within a clonal population (Supplementary Figure 1B). ${ }^{23}$ To correlate directly the levels of active TCMCA3 with the arrest in the S phase, we designed an additional construct where TCMCA3 was fused at the $C$ terminus with the fluorescent reporter eGFP (TCMCA3-eGFP; Figure 4a). We first confirmed by western blot analysis the correct expression of the fusion protein (Figure 4b) and its similar detrimental effect on cell growth (Figure 4c) and cell cycle progression of synchronized epimastigotes (Figure 4d). Next, we combined the analysis of green fluorescence (TCMCA3-eGFP) and red fluorescence (PI) to divide cells into four populations: (eGFP,$+ 2 n),($ eGFP,$+ 4 n)$, (eGFP-, $2 n$ ) and (eGFP-, 4n). The uninduced control cells were mostly eGFP-, although some leaky expression already reported for pTcINDEX can be detected (Figure 4e, first 
d

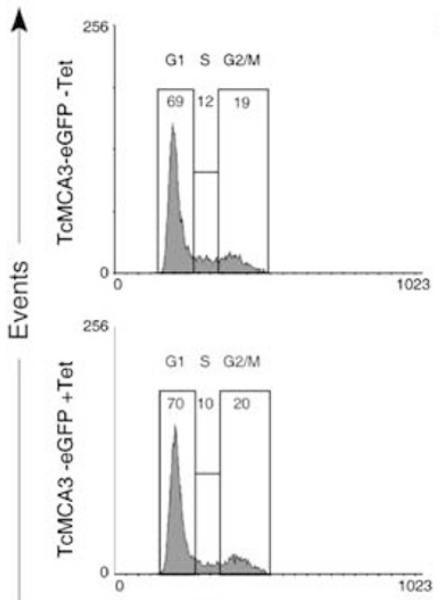

Oh

$48 \mathrm{~h}$
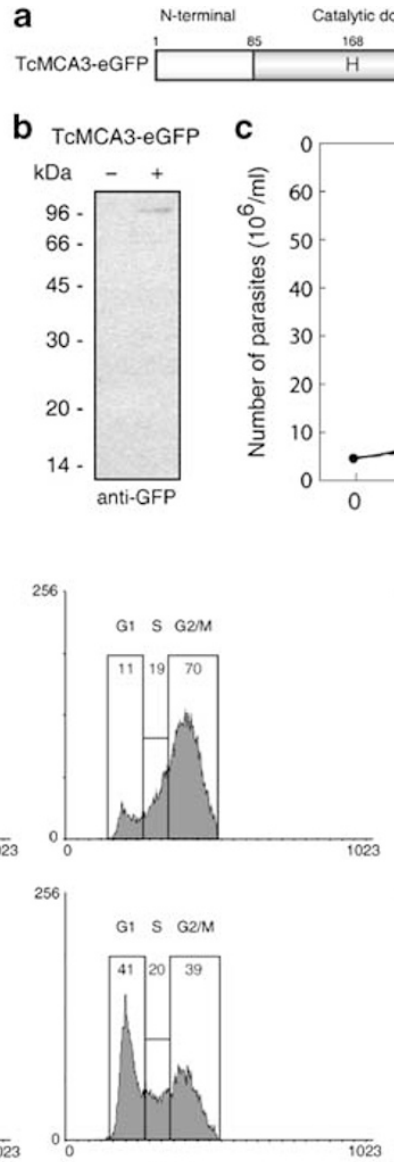

$9 \mathrm{~h}$

$57 \mathrm{~h}$
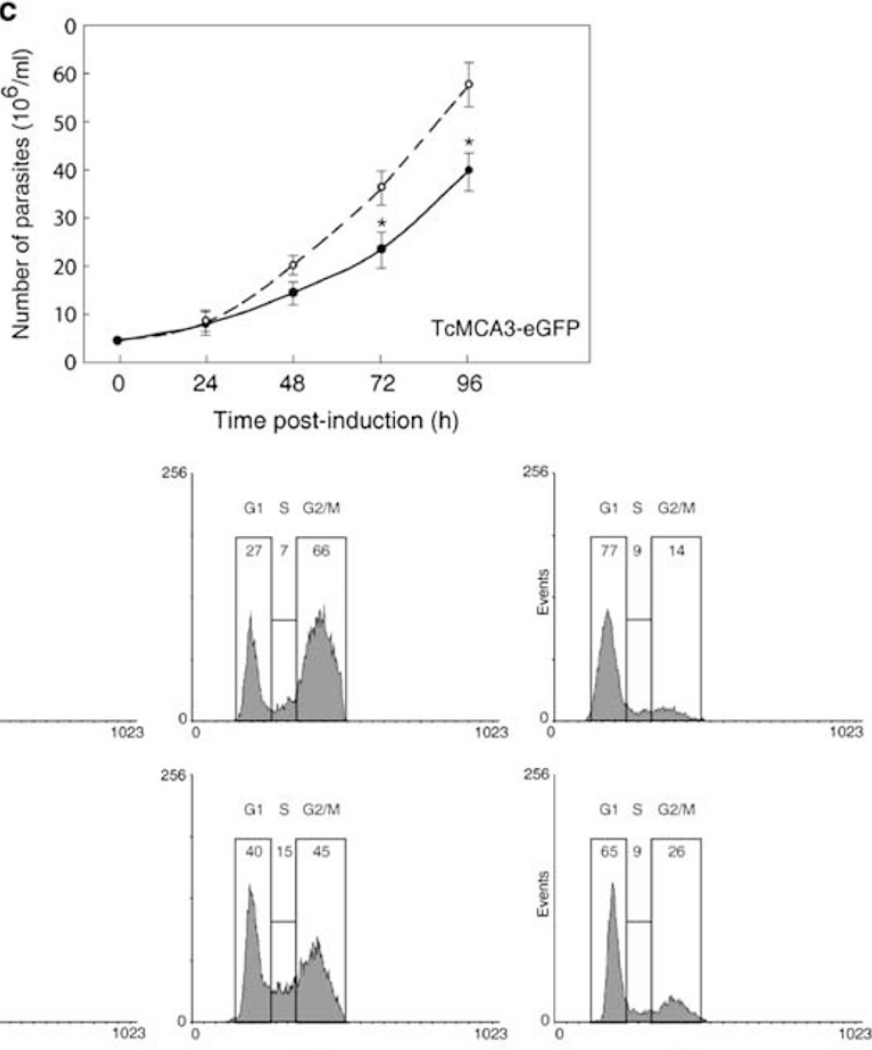

$13 \mathrm{~h}$

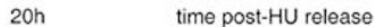

$68 \mathrm{~h} \quad$ time post induction

FL2-A (PI)

e

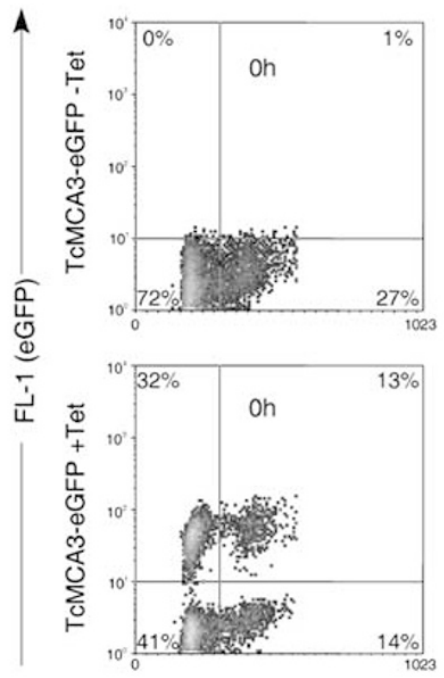

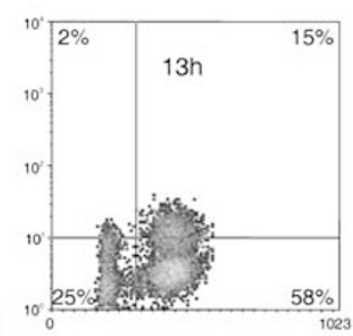
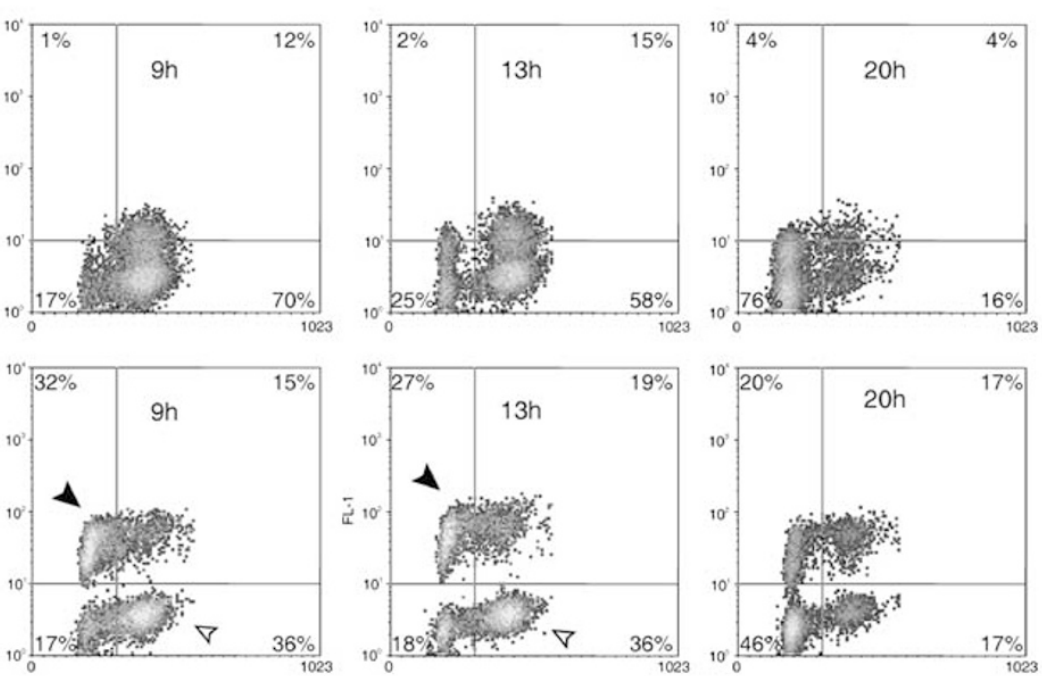

FL2-A (PI)

Figure 4 Metacaspase-3 expression levels correlate with cell cycle arrest. (a) Schematic representation of the fusion protein used as a fluorescent reporter of TcMCA3 expression. (b) TCMCA3-eGFP transgenic epimastigotes were grown in the absence $(-)$ or presence $(+)$ of tetracycline for $60 \mathrm{~h}$ before cell lysates (10 parasites per lane) were prepared and analyzed by western blot with anti-GFP antibody. (c) Growth curve of TcMCA3-eGFP cell line in the presence (closed circles, continuous line) or absence (open circles, dashed line) of tetracycline. (d) Flow cytometry analysis of the cell cycle progression of synchronized TcMCA3-eGFP epimastigotes in the absence (upper row) or in the presence (lower row) of tetracycline. (e) Bivariate dot plots showing the distribution of green fluorescence on the $y$ axis (TCMCA3-eGFP) versus the red fluorescence of $\mathrm{PI}$ staining (representing DNA content) on the $x$ axis. The empty arrowheads depict cells with low TcMCA3-eGFP levels that can progress through the cell cycle. The filled arrowhead shows that cells with a high content of TCMCA3-eGFP remain arrested in the DNA synthesis phase 
row). ${ }^{23,26}$ These cells are clearly progressing through the cell cycle as about $80 \%$ of them had duplicated the DNA content $9 \mathrm{~h}$ after HU removal. In contrast, a dissimilar behaviour can be observed in the induced population (Figure $4 \mathrm{e}$, second row), depending on the TCMCA3-eGFP levels. Cells with low TcMCA3-eGFP levels can progress through the cell cycle (empty arrowhead) resembling the pattern of the uninduced control, whereas cells with high TcMCA3-eGFP content remain arrested in the DNA synthesis phase (filled arrowhead) at $9 \mathrm{~h}$ and still at $13 \mathrm{~h}$ post-HU removal. These data confirm our previous findings and establish a direct correlation between active TcMCA3 levels and cell cycle arrest in G1/S.

Metacaspase-5 lacking the $\mathbf{C}$-terminal extension promotes apoptosis-like cell death. Epimastigote cultures overexpressing active TCMCA5 $\Delta \mathrm{Ct}$ displayed a drop in cell number starting 3 days after protein induction (Figure $2 \mathrm{c}$ ). Microscopic observation of these cultures led to the identification of non-motile rounded cells resembling the apoptotic cells described by Ameisen et al. ${ }^{2}$ (data not shown). When these parasites were synchronized in G1 with $\mathrm{HU}$ and subsequently released, cells were able to cycle normally; however, a sub-G1 peak was evident $68 \mathrm{~h}$ postinduction. Dot plots showing DNA content (PI staining) and forward scatter (FSC) properties of the cells allowed us to follow DNA duplication and cell size increase during cell cycle progression from $\mathrm{G} 1$ to $\mathrm{G} 2$. Using this representation, we detected the presence of hypodiploid cells (Figure 5a, arrow) with reduced volume in cultures of epimastigotes overexpressing TCMCA5 $\Delta \mathrm{Ct}$, but not in the uninduced control or in the induced or uninduced active site mutant. TCMCA5 $\Delta$ Ct could be physiologically relevant as a truncated form with a molecular weight compatible with a C-terminal processing was detected by western blot analysis of epimastigotes in the early stationary phase, when apoptotic-like death occurs (Figure 5b). Expression of active site mutant was higher than wild type, but the band close to $45 \mathrm{kDa}$ can be seen in both lanes with antibodies

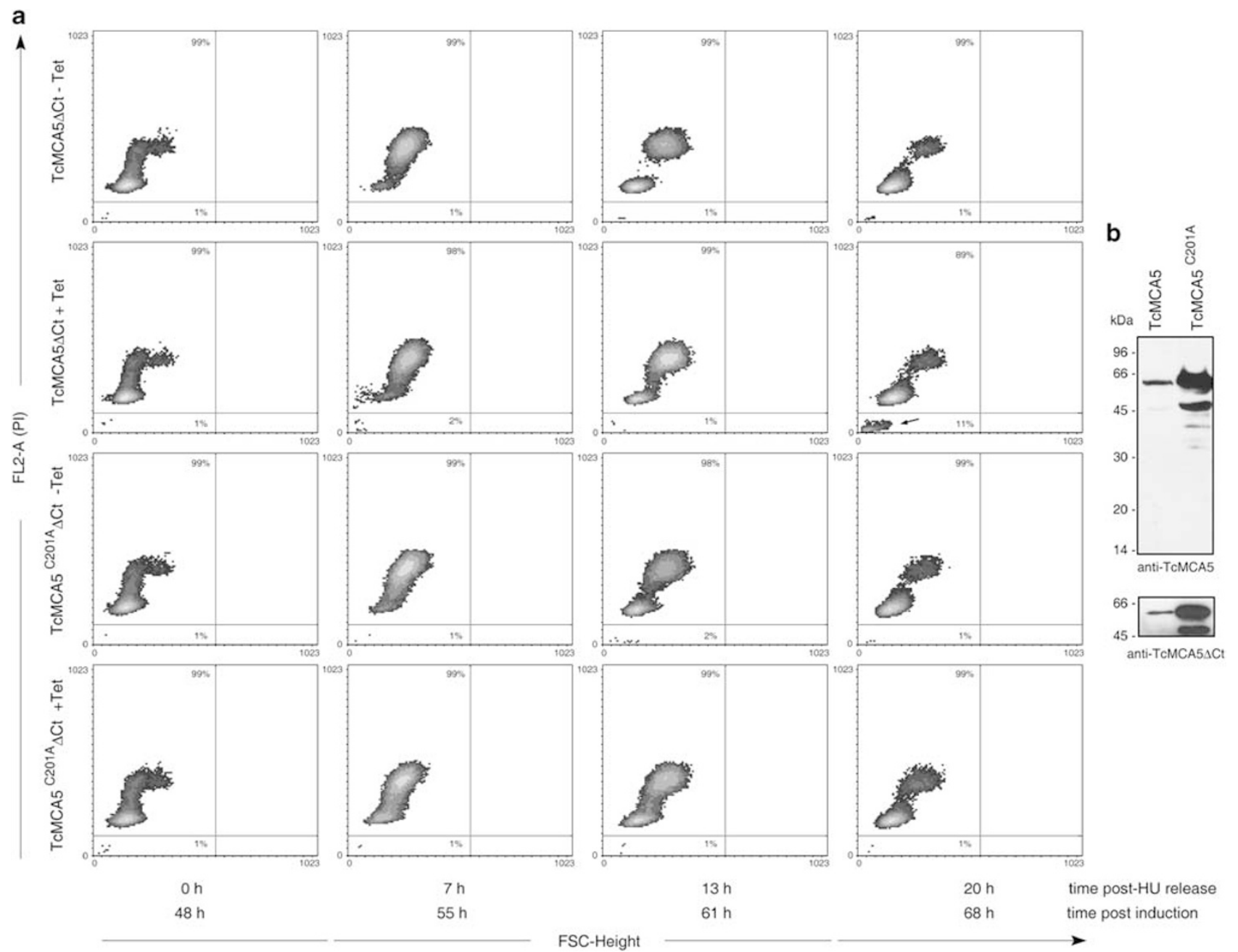

Figure 5 Metacaspase-5 lacking the C-terminal extension promotes apoptosis-like cell death. (a) FACS analysis of cell size (FSC-height) and DNA content (PI) of epimastigotes. Cell lines harbouring transgenes encoding TcMCA5 $\Delta \mathrm{Ct}$ active (C223) or inactive (C223A) grown in the absence $(-)$ or presence $(+)$ of tetracycline. The arrow indicates the appearance of hypodiploid cells in the TCMCA5 $\triangle \mathrm{Ct}$ induced culture. (b) Cell lines harbouring transgenes encoding TcMCA5 active (C201) or inactive $(\mathrm{C} 201 \mathrm{~A})$ were grown in the presence of tetracycline for $72 \mathrm{~h}$ before cell lysates $\left(10^{7}\right.$ parasites per lane) were prepared and analyzed by western blot with anti-TcMCA5 or anti-TCMCA5 $\Delta$ Ct polyclonal antibodies 
raised against full-length or $\Delta \mathrm{Ct}$ proteins. Thus, these results obtained on the evaluation of different markers suggest that TCMCA5 $\Delta \mathrm{Ct}$ could be indeed activating an apoptosis-like cell death pathway in $T$. cruzi based on its catalytic activity. ${ }^{2,27}$

\section{Regulation of metacaspase-3 activity is important for} T. cruzi propagation. As TCMCA3 arrests epimastigotes in G1/S transition, we investigated if this protein was also able to protect them from death naturally occurring during the stationary phase and to promote cell differentiation to the metacyclic trypomastigote (Figure 6a). We evaluated membrane integrity of epimastigotes in late stationary phase by propidium iodide (PI) uptake (Figure 6b) and observed that TcMCA3 activity exerted a pro-survival effect as TCMCA3 overexpressors displayed a reduced percentage of $\mathrm{PI}+$ cells when compared with the uninduced control $(17 \%$ versus $66 \%$ ). Moreover, TCMCA ${ }^{\mathrm{C} 223 \mathrm{~A}}$ overexpressors, likely through a dominant-negative effect, had a notorious reduction in cell viability, suggesting that TCMCA3 activity is essential for cell survival in the early stationary phase. Figure $6 \mathrm{c}$ shows that the number of metacyclics was increased in induced stationary cultures and that metacyclogenesis stimulation was dependent on the catalytic activity of TCMCA3. Inducible protein expression in the stationary phase was confirmed by western blot analysis of both cell lines (data not shown).

To study the importance of metacaspase expression in the replicative form present inside the mammalian host (Figure 6a), we investigated how the transgenic cell lines performed in vitro for the invasion and replication in host cells: trypomastigotes-overexpressing or not TcMCA3-infected Vero cells; however, fewer trypomastigotes were released from infected cells 7 days post-infection when TcMCA3 expression was induced (Figure 6d). Furthermore, microscopic observation of Vero cells stained with 6-diamidino-2phenylindole (DAPI) at 5 days post-infection (Figure 6e) showed a drastic reduction in the number of intracellular amastigotes in TcMCA3-induced cell lines when comparing with the active site mutant. Taken together, our data suggest that a tight regulation of TCMCA3 activity is critical for the cell cycle progression of all $T$. cruzi replicative forms and might also be important for differentiation among life-cycle stages.

\section{Discussion}

There are still many unanswered questions with regard to the biochemical properties and potential roles of metacaspases. ${ }^{16-18,28}$ All metacaspases studied so far are strictly specific for basic amino-acid residues at P1 position when using either synthetic peptides or protein as substrates. ${ }^{9,22,29}$ However, significant differences were found when studying if protein maturation was required for activity. Plant type II, but not type I, metacaspases were clearly shown to be autocatalytically activated in vitro by a cleavage event at the p20-p10 boundary. ${ }^{6}$ Among trypanosomatids, LmMMCA has been reported to undergo self-proteolytic processing in yeast cells overexpressing $L m M M C A$, but not its inactive mutants. ${ }^{30}$ However, neither the processing sites were clearly identified nor further analysis of the recombinant protein was performed to correlate maturation with activity. Nevertheless, the artificial deletion of the C-terminal extension enhanced activity by threefold. In T. brucei, only TbMCA2-3 has been studied, and although some processing was detected, it was not required for the enzymatic activity. ${ }^{29}$ We have now evaluated the potential proteolytic processing of both types of trypanosomatid metacaspases. TCMCA3 and TCMCA5 overexpressed in bacteria did not undergo any self-processing in vitro, even under conditions when the purified proteins were shown to be active (Figures 1d and e). This was further confirmed in vivo by the inducible expression of the enzymes. Both metacaspases presented a similar pattern when compared with their corresponding active site mutants, and were detected mainly as full-length forms not only under normal growth conditions (Figure 2b), but also when epimastigotes were subjected to different kinds of stress (Supplementary Figure 2). Taking all these data together, it seems likely that trypanosomatid metacaspases are closer to type I plant metacaspases and do not need any self-proteolytic processing to be active; however, we cannot discard the possibility of metacaspases being activated in cis under certain specific conditions or in trans by other peptidases.

Accumulating evidence indicates that plant metacaspases can modulate apoptosis during embryogenesis, oxidative stress and the hypersensitive response. ${ }^{10,31,32}$ In contrast, the role of trypanosomatid metacaspases seems to be less certain. Overexpression of full-length TcMCA5 in T. cruzi renders epimastigotes more susceptible to FHS-induced cell death, ${ }^{20}$ and González et al. ${ }^{30}$ have shown that $L$. major metacaspase can replace yeast metacaspase in its pro-cell death action during ageing. However, in T. bruceibloodstream forms, triple metacaspase null mutants $(\Delta m c a 2 / 3, \Delta m c a 5)$ did not prevent cell death induced by prostaglandin $D_{2}$ when compared with wild-type parasites. ${ }^{12}$ Nevertheless, RNA interference of the three MCAs together resulted in a rapid arrest of growth with a delay in kinetoplast segregation and a cytokinesis block. In addition, Ambit et al. ${ }^{13}$ showed that limited levels of $L m M M C A$ are essential for normal cell proliferation. As T. cruzi lacks components necessary for the RNA interference pathway, ${ }^{33}$ and knockout strategies are restricted to non-essential single copy genes, we decided to study metacaspase overexpression in the different life-cycle stages with an inducible vector. ${ }^{23}$ Overexpression of active $T c M C A 3$ in the replicative stages, epimastigotes (Figures 2, 3 and 4) or intracellular amastigotes (Figure 6d), was detrimental for cell growth. This effect was not due to overloading of the proteasome as the overexpression of TCMCA5 variants at similar levels did not produce any cell cycle arrest, and it can be attributed to TcMCA3 catalytic activity, as the active site mutant overexpressors cycled normally (Figure 3). Density plot analysis of TCMCA3-eGFP cell lines demonstrated that a two- to sixfold increase in TCMCA3 levels in epimastigotes was sufficient to arrest the cell cycle in the G1/S transition (Figure 4). Moreover, these levels of TCMCA3 are similar to the levels normally expressed in trypomastigotes (Supplementary Figure 4). We have proteomic evidence for TCMCA3 expression in epimastigotes ${ }^{34}$ and amastigotes, ${ }^{35}$ but the higher expression levels were found in the non-replicative trypomastigote (Supplementary Figure 4). Furthermore, increased TCMCA3 levels were also correlated to an enhanced differentiation to metacyclic trypomastigotes, a 
non-replicative form present in the insect vector that is preadapted to survive in the mammalian host (Figure 6b), and this effect was also dependent on TCMCA3 activity. We have previously shown the involvement of autophagy in this differentiation step. ${ }^{36}$ Differentiation is a very complex process, which involves a number of changes in transcrip- tional and translational profiles, metabolism, surface of the parasite, which changes to protect the metacyclics from the immune response of the host, etc. Regulation of MCA3 levels might be a signal for the arrest of the epimastigotes, an early event in differentiation. The activation of the autophagic pathway, on the other hand, seems to be a later event for the a

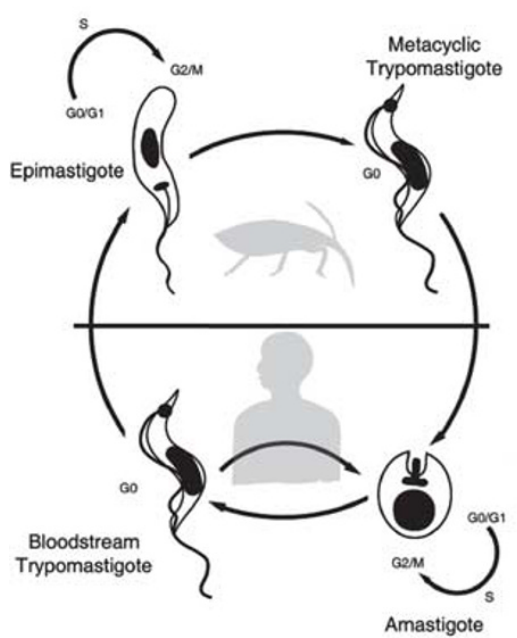

e
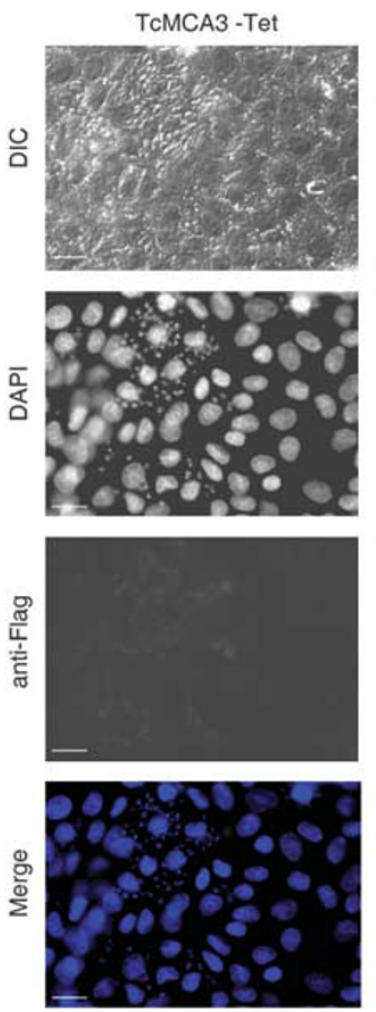

b
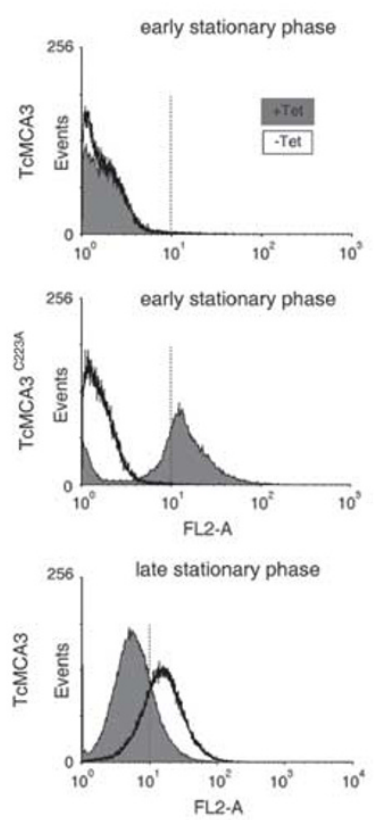

TcMCA3 + Tet
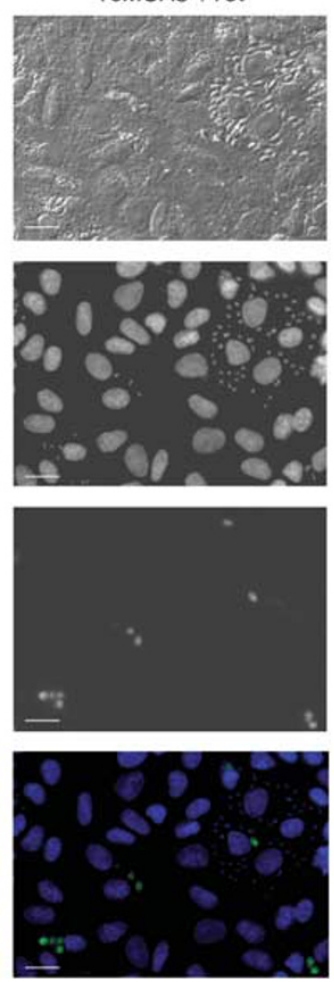
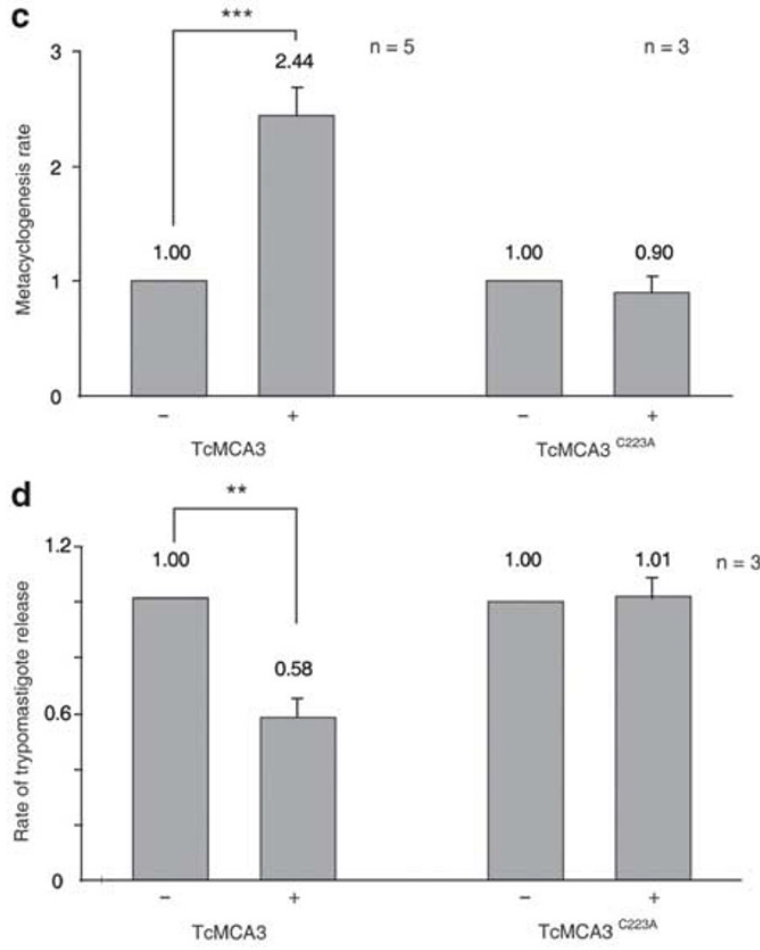

TCMCA3 ${ }^{\text {C223A-Tet }}$

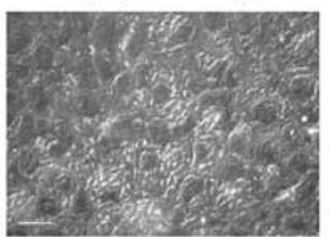

TCMCA3 $^{\text {C223A }^{2}+\text { Tet }}$
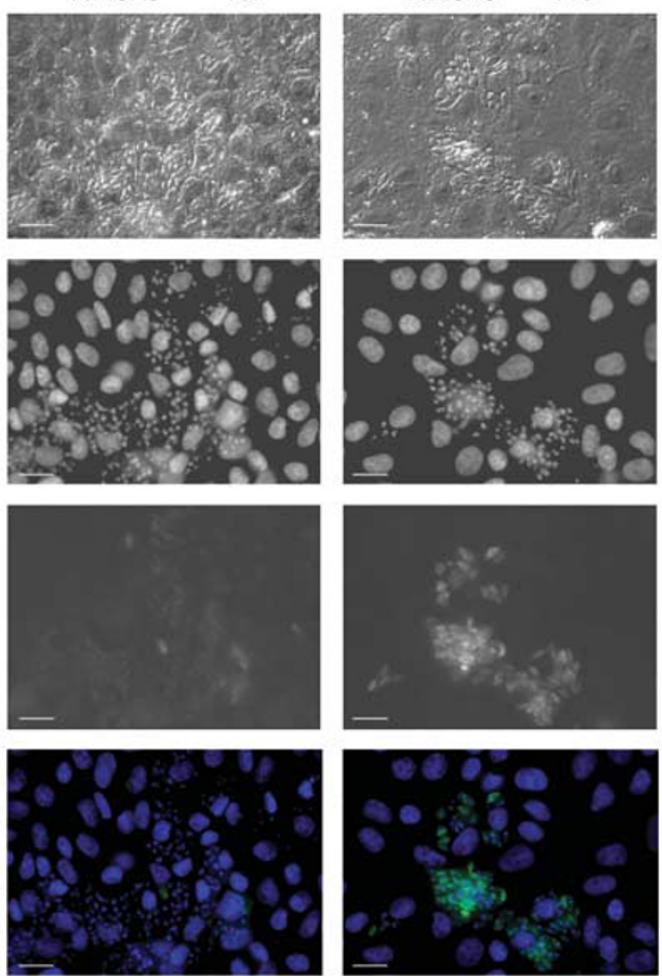
recycling and remodelling processes involved in differentiation.

We also showed for TCMCA5 that its C-terminal extension negatively regulates its ability to promote an apoptotic-like cell death based on its catalytic activity (Figures 2 and 5), suggesting that active TCMCA5 may have a pro-apoptotic role regulated by proteolytic processing of its C-terminal extension, as recently described for $L m M M C A$ by Zalila et al. ${ }^{11}$ The observed difference in phenotypes for TCMCA5 and $T c M C A 5 \Delta \mathrm{Ct}$ overexpressors seems not to be due to a different subcellular distribution of the protein (data not shown), but could be attributed to an enhanced activity, as the artificial deletion of the C-terminal extension in TcMCA5 increases its catalytic efficiency by 2.7 -fold. On the other hand, the $\mathrm{C}$ terminus might maintain the protein in a different conformation, preventing the cleavage activation of proapoptotic proteins. We already have proteomic evidence supporting the latter hypothesis on the basis of differential protein binders to the full-length and the truncated enzyme forms (unpublished results).

In summary, our data suggest that $T$. cruzi metacaspases, although sharing substrate specificity, still have biochemical differences in calcium activation and proteolytic processing that might explain their antagonic effects during the epimastigote stationary phase. In addition, both metacaspases fulfil important roles in cell cycle regulation and apoptosis-like cell death pathways, showing the close relationship between cell division, cell death and cell differentiation in this ancient unicellular eukaryote.

\section{Materials and Methods}

Plasmids. Constructs for bacterial expression: Full-length and truncated versions of metacaspase genes were tagged at the $\mathrm{N}$ terminus with a $6 \times \mathrm{His}-\mathrm{HA}$ tag and at the $\mathrm{C}$ terminus with a $3 \times$ Flag epitope. $\mathrm{N}$-terminal tags were introduced by polymerase chain reaction (PCR) in two consecutive steps, whereas the C-terminal tag was added by cloning the final PCR product in frame with a $3 \times$ Flag present in the arabinose-inducible plasmid vector pBAD24 (please refer to Supplementary Material and Methods and Supplementary Tables S1 and S2 for further details). ${ }^{37}$ Point mutants were generated using Quick Change site-directed mutagenesis kit (Stratagene, La Jolla, CA, USA) and confirmed by DNA sequencing.

Constructs for expression in T. cruzi: To facilitate detection, tagged versions of metacaspases were generated. For TCMCA3, this was achieved by PCR amplification of full-length $T C M C A 3$ and the $\mathrm{C}^{223} \mathrm{~A}$ active site mutant from the pBAD24 constructs used for bacterial expression, followed by subcloning into pTCINDEX vector. ${ }^{23}$ For TCMCA5, the strategy used for expression in the parasite differed from the one used for bacterial expression: the first 18 amino-acid residues encoding a putative signal peptide were included and tags at the $\mathrm{N}$ terminus were avoided. First, full-length $T C M C A 5$ and the truncated form lacking the C-terminal extension were cloned in pBAD24 to promote the fusion to the $3 \times$ Flag epitope present in the vector and then they were subcloned into pTcINDEX vector (Supplementary Materials and Methods and Supplementary Table S3 for a detailed description). For inducible expression of eGFP fusion of TCMCA3 (TCMCA3-eGFP), TCMCA3 and eGFP coding sequences were independently amplified from genomic DNA or pTEX-eGFP, respectively. ${ }^{20}$ Fragments were ligated to generate the fusion product that was then inserted into the pTCINDEX vector. ${ }^{23}$

Recombinant protein expression and purification. Plasmid constructs were used to transform E. coli Bl21 - Codon Plus (Stratagene). Cultures were induced with $0.2 \% \mathrm{~L}-(+)$ arabinose (Calbiochem, Darmstadt, Germany) for $4 \mathrm{~h}$ at $37^{\circ} \mathrm{C}$, harvested by centrifugation at $3000 \times \mathrm{g}$ for $10 \mathrm{~min}$ and pellets were frozen. Cells were thawed at $4^{\circ} \mathrm{C}$ and lysed with Tris-buffered saline (50 mM Tris-HCl (pH 7.6), $100 \mathrm{mM} \mathrm{NaCl}$ (Merck, Darmstadt, Germany)) containing $0.1 \%$ Triton X-100 (Sigma, St. Louis, MO, USA) and $0.1 \mathrm{mg} / \mathrm{ml}$ lysozyme. After sonication, cell debris were removed by centrifugation at $20000 \times g$ for $25 \mathrm{~min}$ at $4{ }^{\circ} \mathrm{C}$ and supernatants were applied to fast flow Ni-NTA columns (Amersham Biosciences, Little Chalfont, UK) pre-equilibrated with binding buffer $(50 \mathrm{mM}$ Tris- $\mathrm{HCl}(\mathrm{pH} 7.6), 500 \mathrm{mM} \mathrm{NaCl})$. The columns were first washed with binding buffer, then with the same buffer supplemented with $30 \mathrm{mM}$ imidazole (Riedel-de Haën, St. Louis, MO, USA), and finally proteins were eluted with binding buffer containing $300 \mathrm{mM}$ imidazole. Eluates containing the recombinant proteins were pooled and the buffer was changed to $50 \mathrm{mM} \mathrm{N}$-(2-hydroxyethyl) piperazine- $\mathrm{N}$-(2ethanesulphonic acid) (Hepes) (pH 7.5) (Sigma), $150 \mathrm{mM} \mathrm{NaCl}, 10 \%$ (v/v) glycerol (Invitrogen, Carlsbad, CA, USA), $10 \mathrm{mM} \mathrm{CaCl}$ (Sigma) and $10 \mathrm{mM}$ dithiothreitol (DTT; Promega, Madison, WI, USA) using PD-10 columns (Amersham Biosciences).

Metacaspase activity assay. Metacaspase activity was evaluated by fluorometric detection of hydrolysis of VRPR-AMC (Bachem, Bubendorf, Switzerland). Assays were performed with $150 \mu \mathrm{M}$ substrate in buffer $50 \mathrm{mM}$ Hepes (pH 7.5), $150 \mathrm{mM} \mathrm{NaCl}, 10 \%$ (v/v) glycerol, $10 \mathrm{mM} \mathrm{CaCl}_{2}$ and $10 \mathrm{mM} \mathrm{DTT} \mathrm{in}$ a final volume of $300 \mu \mathrm{l}$. In all, $20 \mu \mathrm{g}$ of purified recombinant protein was used per reaction. Measurements were collected on an Aminco-Bowman Series 2 Luminescence Spectrometer using excitation and emission wavelengths of $380 \pm 4$ and $460 \pm 4 \mathrm{~nm}$, respectively, and $700 \mathrm{~V}$ of sensitivity.

Electrophoresis and immunoblotting. Proteins were separated by SDS-PAGE (12.5\% acrylamide) and transferred to a nitrocellulose membrane for probing. Polyclonal antibodies were raised in mouse for TCMCA3 and TCMCA5Ct or in rabbit for TCMCA5 against the recombinant purified proteins and were used diluted $1: 1000{ }^{20}$ The HA tag was detected using a high-affinity rat monoclonal antibody (Roche, Bubendorf, Switzerland) diluted 1:1000. The Flag epitope was detected using anti-Flag M2 mouse monoclonal antibody (Sigma) diluted 1: 10000. Low molecular weight markers used were from GE (Little Chalfont, UK). Horseradish peroxidase-conjugated goat anti-rat, goat anti-mouse or goat antirabbit (Calbiochem) were detected by chemiluminescence using SuperSignal West Pico Chemiluminescent Substrate (Pierce, Rockford, IL, USA).

Parasites. Epimastigotes of $T$. cruzi (Tc. I Adriana) ${ }^{38}$ were grown axenically at $28^{\circ} \mathrm{C}$ in a brain-heart infusion-tryptose culture medium (BHT) containing $33 \mathrm{~g} / \mathrm{l}$ brain-heart infusion (Difco), $3 \mathrm{~g} / \mathrm{l}$ tryptose (Difco, Lawrence, KS, USA), $4 \mathrm{~g} / \mathrm{l}$

Figure 6 Metacaspase-3 activity protects epimastigotes from cell death, stimulates differentiation to metacyclics and affects replication inside the mammalian host. (a) Schematic representation of the life cycle of $T$. cruzi. The parasite has a complex life cycle, with four major stages: in the insect vector a replicative stage, the epimastigote and a non-replicative one, the infective metacyclic trypomastigote, are present; in the mammalian host, an obligate intracellular replicative form, the amastigote and a nonreplicative one, invasive for host cells, the bloodstream trypomastigote. These forms differ in size, subcellular organization, in antigenic and some metabolic properties. (b) Epimastigotes were grown for 2 weeks to stationary phase, induced or not with tetracycline and incubated for 1 or 3 weeks more (early and late stationary phase). Histograms show PI uptake in uninduced (empty) or induced (filled) TCMCA3 and TCMCA3 ${ }^{\mathrm{C} 223 \mathrm{~A}}$ cell lines. (c) Metacyclogenesis rate in uninduced $(-)$ or induced $(+)$ cell lines harbouring transgenes encoding TCMCA3, TCMCA3 ${ }^{\mathrm{C2} 23 \mathrm{~A}}$ was evaluated as described in Materials and Methods. Numbers indicate that metacyclogenesis increase relative to the corresponding uninduced control. Means and S.D. from at least three independent experiments are indicated. Differences observed between values were statistically significant (Student's $t$-test). ${ }^{* \star *} P<0.001$. (d) The number of trypomastigotes released after 7 days of infection was evaluated for the same cell lines than in (b). Numbers indicate decrease in trypomastigote release relative to the corresponding uninduced control. Means and S.D. from three independent experiments are indicated. Differences observed between values resulted statistically significant (Student's $t$-test). ${ }^{*} P<0.01$. (e) Evaluation of intracellular amastigotes after 5 days of infection. DIC, DAPI anti-Flag and merged images (DAPI in blue and FLAG in green) of infected Vero cells with induced (+ Tet) or uninduced (-Tet) active or inactive TCMCA3 forms are shown. Bar scales represent $10 \mu \mathrm{m}$ 
$\mathrm{Na}_{2} \mathrm{HPO}_{4}, 0.4 \mathrm{~g} / \mathrm{KCl}$ and $0.3 \mathrm{~g} / \mathrm{l}$ glucose (in addition to $1.7 \mathrm{~g}$ already added as part of the brain-heart infusion), $\mathrm{pH} 7.5$, sterilized $\left(10 \mathrm{~min}\right.$ at $\left.121^{\circ} \mathrm{C}\right)$ and supplemented with haemin $(20 \mu \mathrm{g} / \mathrm{ml})$, penicillin $(100 \mathrm{lU} / \mathrm{ml})$, streptomycin $(100 \mu \mathrm{g} / \mathrm{ml})$ and $10 \%$ (v/v) heat-inactivated foetal calf serum (FCS; Natocor, Córdoba, Argentina). Growth curves were obtained by counting cell number daily using a Neubauer chamber under the light microscope $(\times 400)$. Metacyclic trypomastigotes were obtained by spontaneous differentiation of epimastigotes at $28^{\circ} \mathrm{C}$. Metacyclogenesis rate was evaluated by counting the number of metacyclic trypomastigotes in a Neubauer chamber. Characteristic cell motility, size and shape were used to discriminate metacyclics from epimastigotes. Results were confirmed by recounting the cell number in cultures exposed to $10 \%$ FHS during $4 \mathrm{~h}$, a condition only resisted by the adapted metacyclic form. ${ }^{2}$ Cell-derived trypomastigotes were obtained by infection with metacyclic trypomastigotes of Vero cell monolayers grown in a minimal essential medium Eagle (Gibco, Carlsbad, CA, USA) supplemented with $5 \%$ (v/v) FCS. Cell-derived trypomastigotes were maintained by weekly passage of Vero cell monolayers and used for invasion and intracellular amastigotes proliferation experiments. The number of cell-derived trypomastigotes and intracellular amastigotes was evaluated in a Neubauer chamber and using DAPI staining, respectively.

\section{Generation of metacaspase-transfectant cell lines and protein} overexpression. For inducible expression of metacaspase genes in the parasite, we first generated a cell line expressing T7 RNA polymerase and tetracycline repressor genes by transfecting epimastigotes with the plasmid pLew13 using a standard electroporation method. ${ }^{39}$ Briefly, parasites in the mid-log phase were washed with and resuspended in BHT medium without FCS at a final concentration of $5 \times 10^{8}$ cells per $\mathrm{ml}$. Aliquots of $0.35 \mathrm{ml}$ were dispensed into disposable 0.4-mm cuvettes (Bio-Rad Laboratories, Hercules, CA, USA) containing $10 \mu \mathrm{g}$ of plasmid DNA and cells were electroporated by using a Bio-Rad gene pulser at $335 \mathrm{~V}$ and $1400 \mu \mathrm{F}$, with two consecutive pulses. After 5 min on ice, the cells were diluted 10-fold with BHT medium containing $10 \%$ FCS and allowed to recover for $24 \mathrm{~h}$. Geneticin (G418; Life Technologies, Carlsbad, CA, USA) was added at a concentration of $200 \mu \mathrm{g} / \mathrm{ml}$, and parasites were incubated at $28^{\circ} \mathrm{C}$. After selection, transfected epimastigotes were grown in the presence of $200 \mu \mathrm{g}$ of G418 sulphate per $\mathrm{ml}$. This parental cell line was then transfected with pTcINDEX constructs (see above) and transgenic parasites were obtained after 3 weeks of selection with $200 \mu \mathrm{g} / \mathrm{ml} \mathrm{G} 418$ and $200 \mu \mathrm{g} / \mathrm{ml}$ hygromycin B (Calbiochem). ${ }^{23}$ Epimastigote cultures were grown to reach a cell density of $5-10 \times 10^{6}$ parasites per $\mathrm{ml}$ and protein expression was induced by the addition of $5 \mu \mathrm{g} / \mathrm{ml}$ tetracycline (Sigma). Epimastigotes were harvested by centrifugation at $1000 \times g$ for $5 \mathrm{~min}$, washed twice in Dulbecco's PBS (Gibco) and lysed on ice by incubation with Laemmli's sample buffer for western blot or fixed with $4 \%$ paraformaldehyde (v/v PBS; Electron Microscopy Sciences, Hatfield, PA, USA) for indirect immunofluorescence.

Synchronization of T. cruzi epimastigotes. Epimastigotes were induced or not with tetracycline for $24 \mathrm{~h}$ previous to synchronization using $\mathrm{HU}$ (Sigma) as described previously. ${ }^{24}$ Briefly, mid-log epimastigotes were transferred to fresh BHT medium containing $20 \mathrm{mM} \mathrm{HU}$ at a density of $10^{7}$ cells per $\mathrm{ml}$ and incubated at $28^{\circ} \mathrm{C}$ for $24 \mathrm{~h}$. Cell cycle was released by $\mathrm{HU}$ removal by washing the cells twice with PBS and suspending them in BHT medium at a density of $10^{7}$ cells per $\mathrm{ml}$ with or without the addition of $5 \mu \mathrm{g} / \mathrm{ml}$ tetracycline. Aliquots were removed at different time points and fixed overnight at $4{ }^{\circ} \mathrm{C}$ with $70 \% \mathrm{EtOH}$ (v/v PBS) for fluorescent-activated cell sorting (FACS) cell cycle analysis or resuspended in Laemmli's sample buffer for western blot analysis.

Flow cytometry analysis. For DNA content determination, fixed cells were harvested, resuspended in $500 \mu \mathrm{l}$ of PBS containing $50 \mu \mathrm{g} / \mathrm{ml} \mathrm{PI} \mathrm{(Molecular} \mathrm{Probes,}$ Carlsbad, CA, USA), $20 \mu \mathrm{g} / \mathrm{ml}$ RNAse A and $2 \mathrm{mM}$ EDTA and incubated at $37^{\circ} \mathrm{C}$ for $30 \mathrm{~min}$. For evaluation of membrane integrity, live parasites were stained with $50 \mu \mathrm{g} /$ $\mathrm{ml} \mathrm{PI}$. FACS analysis was performed with a Beckton Dickinson FACSCalibur using the FL1 (detecting fluorescence emission between 515 and $545 \mathrm{~nm}$ ), FL2-A (detecting fluorescence emission between 543 and $627 \mathrm{~nm}$ ), the FSC (relative cell size) and the side scatter detectors (cell granulometry or internal complexity). A total of 10000 gated events were collected for each sample. Data were interpreted using the WinMDI 2.9 software (Scripps Research Institute, La Jolla, CA, USA).

Immunofluorescence studies. Epimastigotes were layered onto poly(L-lysine)-precoated cover slips. Vero monolayers were grown directly on cover slips, infected with cell-derived trypomastigotes, fixed with $4 \%$ paraformaldehyde (v/v PBS) for $15 \mathrm{~min}$ and washed twice with PBS. Cover slips were saturated in blocking buffer ( $2 \%$ bovine serum albumin, $0.1 \%$ saponin, $3 \%$ goat serum in PBS) for $30 \mathrm{~min}$ and incubated for $1 \mathrm{~h}$ with primary antibody diluted in $2 \%$ bovine serum albumin and $0.1 \%$ saponin in PBS. Antibodies were used diluted $1: 1000$ for antiFlag M2 mouse monoclonal antibody (Sigma), rabbit anti-Flag polyclonal antibodies (Sigma) and anti-TCMCA3 polyclonal antibodies. Cover slips were washed with PBS and incubated with the secondary antibody AlexaFluor 488-conjugated goat anti-rabbit immunoglobulins (Molecular Probes) (1:1000 diluted in 2\% bovine serum albumin, $0.1 \%$ saponin in PBS) for $1 \mathrm{~h}$. After extensive washing with PBS, cover slips were mounted using FluorSave reagent (Calbiochem) containing $5 \mu \mathrm{g} / \mathrm{ml}$ DAPI (Molecular Probes). Slides were examined on an Eclipse E600 fluorescence microscope (Nikon) and image capture was performed by a Spot RT Slider Model No. 2.3.1 digital camera (Diagnostic Instruments, Sterling Heights, MI, USA).

Statistical analysis. All values are presented as mean \pm S.E.M. Statistical analysis was performed using the one-tailed unpaired Student's $t$-test. The significant differences were ${ }^{\star} P<0.05,{ }^{* \star} P<0.01$ and ${ }^{* \star} P<0.001$.

\section{Conflict of Interest}

The authors declare no conflict of interest.

Acknowledgements. This study was supported by PICT 200602381 from the Agencia Nacional de Promoción Científica y Tecnológica (ANPCyT, MinCyT, Argentina) to JJC and Fogarty International Center (Grant Number D43TW007888) to VEA; ML had fellowships from AMSUD-PASTEUR, ANPCyT and Argentinean National Research Council (CONICET). JJC and VEA are members of the research career of the CONICET. We greatly appreciate discussion of the manuscript with Dr. Gregor Kosec. We thank John Kelly and Martin Taylor (London School of Tropical Medicine, London, UK) for kindly providing the pTcINDEX and pTEX-eGFP expression vectors. We also thank Gaston Ortiz for helping with FACS experiments.

1. Barrett MP, Burchmore RJS, Stich A, Lazzari JO, Frasch AC, Cazzulo JJ et al. The trypanosomiases. Lancet 2003; 362: 1469-1480.

2. Ameisen JC, Idziorek T, Billaut-Mulot O, Loyens M, Tissier JP, Potentier A et al. Apoptosis in a unicellular eukaryote (Trypanosoma cruzi): implications for the evolutionary origin and role of programmed cell death in the control of cell proliferation, differentiation and survival. Cell Death Differ 1995; 2: 285-300.

3. van Zandbergen G, Bollinger A, Wenzel A, Kamhawi S, Voll R, Klinger M et al. Leishmania disease development depends on the presence of apoptotic promastigotes in the virulent inoculum. Proc Natl Acad Sci USA 2006; 103: 13837-13842.

4. Irigoín F, Inada NM, Fernandes MP, Piacenza L, Gadelha FR, Vercesi AE et al. Mitochondrial calcium overload triggers complement-dependent superoxide-mediated programmed cell death in Trypanosoma cruzi. Biochem J 2009; 418: 595-604.

5. Uren AG, O'Rourke K, Aravind LA, Pisabarro MT, Seshagiri S, Koonin EV et al. Identification of paracaspases and metacaspases: two ancient families of caspase-like proteins, one of which plays a key role in MALT lymphoma. Mol Cell 2000; 6: 961-967.

6. Vercammen D, de Cotte van B, De Jaeger G, Eeckhout D, Casteels P, Vandepoele K et al. Type II metacaspases Atmc4 and Atmc9 of Arabidopsis thaliana cleave substrates after arginine and lysine. J Biol Chem 2004; 279: 45329-45336.

7. Madeo F, Herker E, Maldener C, Wissing S, Lächelt S, Herlan M et al. A caspase-related protease regulates apoptosis in yeast. Mol Cell 2002; 9: 911-917.

8. Suarez MF, Filonova LH, Smertenko A, Savenkov El, Clapham DH, Arnold von S et al. Metacaspase-dependent programmed cell death is essential for plant embryogenesis. Curr Biol 2004; 14: R339-R340.

9. Sundström JF, Vaculova A, Smertenko AP, Savenkov El, Golovko A, Minina E et al. Tudor staphylococcal nuclease is an evolutionarily conserved component of the programmed cell death degradome. Nat Cell Biol 2009; 11: 1347-1354.

10. Coll NS, Vercammen D, Smidler A, Clover C, Van Breusegem F, Dangl JL et al. Arabidopsis type I metacaspases control cell death. Science 2010; 330: 1393-1397.

11. Zalila H, González IJ, El-Fadili AK, Delgado MB, Desponds C, Schaff C et al. Processing of metacaspase into a cytoplasmic catalytic domain mediating cell death in Leishmania major. Mol Microbiol 2011; 79: 222-239.

12. Helms MJ, Ambit A, Appleton P, Tetley L, Coombs GH, Mottram JC. Bloodstream form Trypanosoma brucei depend upon multiple metacaspases associated with RAB11-positive endosomes. J Cell Sci 2006; 119 (Part 6): 1105-1117.

13. Ambit A, Fasel N, Coombs GH, Mottram JC. An essential role for the Leishmania major metacaspase in cell cycle progression. Cell Death Differ 2008; 15: 113-122.

14. Lee REC, Puente LG, Kaern M, Megeney LA. A non-death role of the yeast metacaspase: Yca1p alters cell cycle dynamics. PLoS One 2008; 3: e2956. 
15. Lee REC, Brunette S, Puente LG, Megeney LA. Metacaspase Yca1 is required for clearance of insoluble protein aggregates. Proc Natl Acad Sci USA 2010; 107: 13348-13353.

16. Tsiatsiani L, Van Breusegem F, Gallois P, Zavialov A, Lam E, Bozhkov PV. Metacaspases. Cell Death Differ 2011; 18: 1279-1288.

17. Carmona-Gutierrez D, Fröhlich KU, Kroemer G, Madeo F. Metacaspases are caspases. Doubt no more. Cell Death Differ 2010; 17: 377-378.

18. Enoksson M, Salvesen GS. Metacaspases are not caspases - always doubt. Cell Death Differ 2010; 17: 1221.

19. Berg M, Van der Veken P, Joossens J, Muthusamy V, Breugelmans M, Moss CX et al. Design and evaluation of Trypanosoma brucei metacaspase inhibitors. Bioorg Med Chem Lett 2010; 20: 2001-2006.

20. Kosec G, Alvarez VE, Agüero F, Sánchez D, Dolinar M, Turk B et al. Metacaspases of Trypanosoma cruzi: possible candidates for programmed cell death mediators. Mol Biochem Parasitol 2006; 145: 18-28.

21. Lamkanfi M, Festjens N, Declercq W, Vanden Berghe T, Vandenabeele P. Caspases in cell survival, proliferation and differentiation. Cell Death Differ 2007; 14: 44-55.

22. Vercammen D, Belenghi B, de Cotte van B, Beunens T, Gavigan J-A, De Rycke R et al. Serpin1 of Arabidopsis thaliana is a suicide inhibitor for metacaspase 9. J Mol Biol 2006; 364: 625-636.

23. Taylor MC, Kelly JM. pTCINDEX: a stable tetracycline-regulated expression vector for Trypanosoma cruzi. BMC Biotechnol 2006; 6: 32

24. Galanti N, Dvorak JA, Grenet J, McDaniel JP. Hydroxyurea-induced synchrony of DNA replication in the kinetoplastida. Exp Cell Res 1994; 214: 225-230.

25. Proto WR, Castanys-Munoz E, Black A, Tetley L, Moss CX, Juliano L et al. Trypanosoma brucei metacaspase 4 is a pseudopeptidase and a virulence factor. J Biol Chem 2011; 286: 39914-39925.

26. Piacenza L, Irigoín F, Alvarez MN, Peluffo G, Taylor MC, Kelly JM et al. Mitochondria superoxide radicals mediate programmed cell death in Trypanosoma cruzi. cytoprotective action of mitochondrial iron superoxide dismutase overexpression. Biochem J 2007; 403 323-334.

27. Kroemer G, Galluzzi L, Vandenabeele P, Abrams J, Alnemri ES, Baehrecke EH et al Classification of cell death: recommendations of the Nomenclature Committee on Cell Death 2009. Cell Death Differ 2009; 16: 3-11.
28. Vercammen D, Declercq W, Vandenabeele P, Van Breusegem F. Are metacaspases caspases? J Cell Biol 2007; 179: 375-380.

29. Moss CX, Westrop GD, Juliano L, Coombs GH, Mottram JC. Metacaspase 2 of Trypanosoma brucei is a calcium-dependent cysteine peptidase active without processing. FEBS Lett 2007; 581: 5635-5639.

30. González IJ, Desponds C, Schaff C, Mottram JC, Fasel N. Leishmania major metacaspase can replace yeast metacaspase in programmed cell death and has arginine-specific cysteine peptidase activity. Int J Parasitol 2007; 37: 161-172.

31. Bozhkov PV, Suarez MF, Filonova LH, Daniel G, Zamyatnin AA, Rodriguez-Nieto S et al. Cysteine protease mcll-Pa executes programmed cell death during plant embryogenesis. Proc Natl Acad Sci USA 2005; 102: 14463-14468.

32. He R, Drury GE, Rotari VI, Gordon A, Willer M, Farzaneh T et al. Metacaspase-8 modulates programmed cell death induced by ultraviolet light and $\mathrm{H}_{2} \mathrm{O}_{2}$ in Arabidopsis. $J$ Biol Chem 2008; 283: 774-783.

33. DaRocha W, Otsu K, Teixeira SMR, Donelson JE. Tests of cytoplasmic RNA interference (RNAi) and construction of a tetracycline-inducible $\mathrm{T7}$ promoter system in Trypanosoma cruzi. Mol Biochem Parasitol 2004; 133: 175-186.

34. Bayona JC, Nakayasu ES, Laverrière M, Aguilar C, Sobreira TJP, Choi H et al. SUMOylation pathway in Trypanosoma cruzi: functional characterization and proteomic analysis of target proteins. Mol Cell Proteomics 2011; 10: M110.00736.

35. Atwood JA, Weatherly DB, Minning TA, Bundy B, Cavola C, Opperdoes FR et al. The Trypanosoma cruzi proteome. Science 2005; 309: 473-476.

36. Alvarez VE, Kosec G, Sant'Anna C, Turk V, Cazzulo JJ, Turk B. Autophagy is involved in nutritional stress response and differentiation in Trypanosoma cruzi. J Biol Chem 2008; 283: 3454-3464.

37. Guzman LM, Belin D, Carson MJ, Beckwith J. Tight regulation, modulation, and high-leve expression by vectors containing the arabinose PBAD promoter. J Bacteriol 1995; 177 : 4121-4130.

38. Urban I, Boiani Santurio L, Chidichimo A, Yu H, Chen X, Mucci J et al. Molecular diversity of the Trypanosoma cruzi TcSMUG family of mucin genes and proteins. Biochem $\mathrm{J} 2011$; 438: 303-313.

39. Wirtz $\mathrm{E}$, Leal $\mathrm{S}$, Ochatt $\mathrm{C}$, Cross $\mathrm{GA}$. A tightly regulated inducible expression system for conditional gene knock-outs and dominant-negative genetics in Trypanosoma brucei. Mol Biochem Parasitol 1999; 99: 89-101.

Supplementary Information accompanies the paper on Cell Death and Differentiation website (http://www.nature.com/cdd) 